\title{
Beyond Nutrition Recommendations: What Healthcare Professionals Should Know about Dietary Supplements to Best Serve Their Patients
}

\author{
Jacquelyn C. Pence, Keith R. Martin, Richard J. Bloomer* \\ Center for Nutraceutical and Dietary Supplement Research, College of Health Sciences, University of Memphis, Memphis, TN, \\ USA \\ Email: ^rblooomer@memphis.edu
}

How to cite this paper: Pence, J.C., Martin, K.R. and Bloomer, R.J. (2021) Beyond Nutrition Recommendations: What Healthcare Professionals Should Know about Dietary Supplements to Best Serve Their Patients. Health, 13, 334-346.

https://doi.org/10.4236/health.2021.134027

Received: January 5, 2021

Accepted: April 6, 2021

Published: April 9, 2021

Copyright $\odot 2021$ by author(s) and Scientific Research Publishing Inc. This work is licensed under the Creative Commons Attribution International License (CC BY 4.0).

http://creativecommons.org/licenses/by/4.0/

\section{(c) (i) Open Access}

\begin{abstract}
Although whole food nutrition will likely influence physical health more than any other lifestyle component besides exercise, the use of dietary supplements among men and women continues to be high. Due to this fact, it is imperative that healthcare professionals understand how supplements may impact overall health and wellness of their patients. With the majority of adults taking some form of dietary supplements and many concomitantly taking prescription medications, healthcare providers should be conscientious of adverse effects and interactions that may occur between dietary supplements and prescription drugs. As many consumers are misled by false marketing, healthcare providers should encourage them to be wary of exaggerated claims and direct them to products that are scientifically supported and safe. Continuing education for healthcare providers on dietary supplements is crucial, with new dietary supplement products constantly reaching the markets, in addition to new findings being made through clinical research and case studies. While some dietary supplements provide no meaningful benefit, many dietary supplements have been identified that can be used to ameliorate nutritional deficiencies and reduce the risk of some common health conditions. Others can serve to improve mental and physical performance, while truly enhancing health. This article presents relevant information on dietary supplements that will be useful to the healthcare professional.
\end{abstract}

\section{Keywords}

Dietary Supplements, Nutraceuticals, Healthcare Professionals, Adverse Events 


\section{Introduction}

Healthcare providers are often asked nutrition-specific questions by their patients. While many understand the importance of whole food nutrition in improving overall health, most do not feel comfortable providing nutrition-related advice and often refer patients to a registered dietitian/nutritionist for consultation, which is a wise decision. The dilemma arises when patients inquire about the use of specific dietary supplements. Most healthcare providers know little about such products and are not certain as to whom they can refer patients to, as no one educational discipline trains students in this particular area. Clearly, healthcare providers must take it upon themselves to learn as much as possible, so they can at least be armed with the essential information to help their patients. As the use of dietary supplements reaches an all-time high, it is imperative that healthcare professionals understand how supplements may impact the overall health and wellness of their patients.

Established by the United States Congress, The Dietary Supplement Health and Education Act of 1994 (DSHEA) defines dietary supplements as products that are intended to supplement a diet [1]. These products may contain vitamins, minerals, amino acids, botanicals, and herbs. According to the 2019 publication of the Consumer Survey on Dietary Supplements, which is conducted annually by the Council for Responsible Nutrition, $77 \%$ of U.S. adults take dietary supplements [2]. The highest usage (81\%) was reported from ages $35-54$ years old, with second highest usage being $70 \%$ among 18 - 34 year-old adults. Usage was very similar between males and females. Vitamins and minerals continue to be the most consumed dietary supplement, with $76 \%$ of respondents taking them during the past year. This was followed by specialty supplements (40\%), herbal and botanicals (39\%), sports nutrition supplements (28\%), and weight management supplements (17\%). Supplements were often consumed to fill nutrient gaps or for energy, immune health, healthy aging, or heart health. Based on these statistics, healthcare providers should be at least somewhat familiar with dietary supplements in order to guide patients in making informed decisions.

\section{Dietary Supplements and the Healthcare Provider}

All healthcare providers who engage in direct patient care are in a unique position to share valuable information with their patients regarding nutrition, including dietary supplementation. In the United States, micronutrient deficiencies (low levels of certain vitamins and minerals) are common. Analyses of The National Health and Nutrition Examination Survey (NHANES) intake data have repeatedly identified micronutrient deficiencies and inadequacies within the US population and the amelioration of dietary shortcomings through multivitamin-mineral supplements [3] [4] [5]. The Dietary Guidelines Advisory Committee to the US Department of Health and Human Services and Agriculture has identified the following nutrients as generally deficient in the adult population: 
vitamins $\mathrm{A}, \mathrm{C}, \mathrm{D}$ and $\mathrm{E}$, as well as choline, calcium, magnesium, iron, and potassium [6] [7]. In the lay press, we most frequently hear of iron, zinc, vitamin $B_{12}$, and vitamin $\mathrm{D}$ as the nutrients in which the greatest number of people are deficient, potentially leading to metabolic-related health problems.

In addition to dietary intake data, results of blood tests may also be used to identify deficiencies. Biochemical data from 2003-2006 NHANES found that $31 \%$ of Americans were at risk of anemia or a nutritional deficiency for at least one vitamin, with the risk greatly decreasing when a multivitamin-mineral supplement was consumed [8]. Analysis of aggregate biochemical data from 2001-2012 showed the risks of deficiency for vitamins B6, B12, C, and D were decreased by well over half with regular multivitamin-mineral supplementation [3]. However, a small risk of exceeding the upper limits for some micronutrients was also observed. Healthcare providers should first and foremost discuss the importance of a healthy, whole food nutrition plan with their patients and ideally refer them to a registered dietician for further guidance. Multivitamin-mineral supplements can then be recommended with more certainty/confidence to ameliorate any nutritional deficiencies that may remain.

Although dietary supplements, by definition, are intended to remedy nutritional shortcomings, many people take dietary supplements to prevent or treat health conditions [9]. Healthcare providers must, therefore, be knowledgeable about dietary supplements beyond their basic nutritional utility. Unfortunately, it is well known and understood that education of healthcare providers in the area of nutrition is lacking, and education on dietary supplements is severely lacking or perhaps nonexistent in most cases [10] [11] [12] [13]. During the 25-year period following the enactment of DSHEA, the dietary supplement market size increased from $\$ 4$ billion to $\$ 40$ billion [14]. Considering this fact, it is important that healthcare providers receive some essential education on dietary supplements and stay abreast of the activities and trends in the dietary supplement industry in general, as this industry is always expanding. This may involve self-study and/or the attendance and participation in webinars and workshops specific to dietary supplements and delivered by someone with a great deal of expertise in this area.

\section{Possible Adverse Events, Supplement-Drug Interactions, and Reporting}

With the majority of adults taking some form of dietary supplements and many concomitantly taking prescription medications [15], healthcare providers should be conscientious of adverse effects [16] [17] [18] and interactions that may occur between dietary supplements and prescription drugs [19] [20]. The risk of adverse events and interactions increases with comorbidities and increasing number of prescription drugs [21]. Unfortunately, most patients do not voluntarily disclose dietary supplement use. Thus, it is critical that healthcare providers initiate the conversation with their patients and encourage them to bring the 
original packaging of all supplements they are taking to office visits. One study found that thousands of patients are seen each year in emergency rooms or are hospitalized due to unexpected dietary supplement adverse events [18]. Among the reviewed cases, cardiac symptoms were reported with the consumption of some weight-loss and energy supplements, while gastrointestinal issues were reported for iron and potassium. Another study noted serious cardiovascular, gastrointestinal, and nervous issues with adverse events most common for weight loss and glycemic products [17]. Some dietary supplements may also alter the effectiveness of some prescription drugs. For example, vitamin $\mathrm{K}$ can interfere with warfarin in preventing blood clots, which can be life threatening for some patients [22]. Additionally, tyramine found in aged cheeses and some supplements may cause high blood pressure for patients taking monoamine oxidase inhibitors (MAOIs) [23]. St. John's Wort can interfere with the metabolism of many prescribed medications and therefore has serious clinical implications [20].

New products constantly reaching the markets, in addition to new findings from clinical research and case studies on dietary supplement and drug interactions, necessitates continuous education on dietary supplements for healthcare providers [16]. In 2004, the US Food and Drug Administration's (FDA) Center for Food Safety and Applied Nutrition (CFSAN) introduced the CFSAN Adverse Event Reporting System (CAERS) to monitor adverse effects for dietary supplements [24]. In order to assist with pharmacovigilance (also known as drug safety), a useful database resource based on the CFSAN system has been developed for dietary supplements [25]. Healthcare providers may subscribe to publications such as Nutraceuticals World, Natural Products Insider, or Nutrition Examination Research Digest (NERD) to keep up to date on the industry and can search for studies registered on clinicaltrials.gov. Additional dietary supplement resources, drug interaction databases, and texts are summarized by the American Dietetic Association [26] and the publication by Asher [19].

During health conversations with patients, physicians may become aware of adverse effects potentially associated with dietary supplements. Should this occur, patients should be encouraged to stop taking the supplement to determine if a side effect disappears [16]. If an adverse event is linked to a particular supplement, reporting the event, while not required, is important. For any safety concerns, consumers and healthcare workers should complete a safety report through the Safety Reporting Portal provided by the FDA [10]. While reporting is voluntary for providers and consumers, the Dietary Supplement and Nonprescription Drug Consumer Protection Act requires manufactures to report severe post market adverse events [27].

\section{Dietary Supplement Oversight and Research}

The DSHEA provided the US Food and Drug Administration (FDA) the authority to oversee the quality, safety, and labeling of supplements [1]. Later, the Pub- 
lic Health and Security and Bioterrorism Preparedness and Response Act required all food and supplement manufacturers to register with the FDA [28]. The FDA has the authority to recall adulterated food and dietary supplements as well as foods and supplements with inadequate allergen labels [1] [29] [30]. Additionally, the FDA can recall a post-marketed product if it is deemed unsafe. Unlike drug manufacturers, dietary supplement companies are not required to provide evidence of effectiveness before a supplement can be brought to the public market, thus they are regulated "post market." The requirements for proof of safety and efficacy are also less rigorous than for prescription drugs [16]. While regulations are in place to protect patients, healthcare providers need to provide guidance to help them make informed decisions. This is particularly important because many consumers fall prey to false marketing and should be encouraged to be wary of exaggerated claims.

While dietary supplement companies cannot claim that their products "diagnose, cure, mitigate, treat, or prevent a disease", they can make certain health claims, viz., structure-function claims [31]. The FDA supports claims with Significant Scientific Agreement (SSA), including the use of calcium and vitamin D for osteoporosis, as well as folic acid for neural tube defect [32]. Another example is that of eicosapentaenoic acid (EPA) and docosahexaenoic (DHA) omega-3 fatty acids reducing the risk of hypertension and cardiovascular disease [33]. The FTC monitors dietary supplement claims in advertising; however, dietary supplements companies continue to tout illegal, unproven assertions [34]. In 2012 , a review of 127 weight-loss dietary supplements found that $20 \%$ had made illegal claims [35]. In addition to health claims, patients need to be aware of the possibility that hazardous materials, such as contaminants and prescription drugs may be present in some supplements [36].

Research is rapidly expanding, as the marketplace is increasing internationally [37]. As supplement demand develops, the need for scientific research also increases. Scientists agree that more scientific research on the potential health benefits and risks of dietary supplements is needed; however, there is no consensus on methodology or priorities [38] [39]. Generally, all can agree that quality, safety, and efficacy should be top priorities. Some dietary supplement companies also support research, either through funding of studies or providing products for investigation [40]. Like prescription drugs, the FDA Amendments Act of 2007 (FDAAA) requires certain dietary supplement studies to be registered as clinical trials [41]. However, differences exist between prescription drug and dietary supplement trials (e.g., number of studies registered, study population characteristics) [42]. While dietary supplement studies are not typically as large as drug studies (often due to the cost associated with running a large clinical trial), a review of the literature confirms that there are certainly many well-designed dietary supplement studies. The United States government also supports dietary supplement research; The National Institute of Health's (NIH) Office of Dietary Supplements (ODS) aims to support dietary supplement re- 
search and knowledge and funded \$10.4 million of research in FY 2019 [43]. These studies may be accessed through the NIH database and PubMed.

\section{Scientifically Supported Dietary Supplements}

Although many dietary supplements may be considered unnecessary and have little to no evidence supporting their use, there do exist many products with proven efficacy. This has been borne out through both well-controlled human studies, in addition to years of anecdotal experience with individuals consuming the products. A brief sample of those dietary supplements is presented below.

\subsection{Anti-Inflammatory Agents}

A variety of dietary supplements have evidence indicating a reduction in inflammation. These including omega-3 fatty acids/fish oil [44], alpha lipoic acid [45], tart cherry [46], methylsulfonylmethane (MSM) [47], and ginger root [48], among others [49] [50].

\subsection{Calcium}

Calcium consumption can reduce the risk of osteoporosis [51]. Those at risk for calcium deficiency include individuals who do not consume dairy products and women with low estrogen levels. The daily recommended intake varies with age and the upper limits should be followed. Consuming too much calcium can have adverse health effects including renal insufficiency, vascular and soft tissue calcification, hypercalciuria (excess calcium in urine), and kidney stones.

\subsection{Coenzyme Q10}

Coenzyme Q10 has been found to lower the risk of complications following cardiac surgery and may help reduce the risk of cardiovascular disease, although further research is necessary [52] [53]. A meta-analysis found that Coenzyme Q10 can relieve statin-related muscle pain [54]. Coenzyme Q10 may also help prevent migraines [52].

\subsection{Vitamin D}

Vitamin D consumption to reduce the risk of osteoporosis is scientifically supported [55]. Those at risk of vitamin D deficiency include breastfed infants, older adults, people with limited sun exposure, people with a dark complexion, those with fat malabsorption issues, and individuals with obesity. Other uses for vitamin $\mathrm{D}$, such as to reduce cancer risk and manage type II diabetes, do not have substantial scientific support to date.

\subsection{Eye Health}

The National Institutes of Health has funded two large clinical trials to treat age-related macular degeneration. A dietary supplement was developed from the first study, Age-Related Eye Disease Study (AREDS), which contained a combi- 
nation of vitamin C, vitamin E, beta-carotene, copper, and zinc. From the results of the second study, AREDS2, lutein and zeaxanthin were added to the supplement formulation [56].

\subsection{Folic Acid}

Folic acid, the dietary supplement and food fortifier form of folate, prevents neural tube defects and may help prevent cancer [57]. It is also being studied for potential benefits to a variety of health conditions including preterm birth, congenital birth defects, autism, heart disease, and stroke. Those at risk for folate inadequacy include women of childbearing age, people with alcohol use disorders, and people with nutrient absorption disorders.

\subsection{Omega-3 Fatty Acids/Fish Oils}

The three main omega-3 fatty acids studied are alpha-linolenic acid (ALA), EPA, and DHA [58]. ALA is mostly found in plant oils, while EPA and DHA are found in animals, namely seafood or fish oil. The levels of EPA and DHA vary depending on fish type and whether they are farmed or wild. Overall, research suggests that omega-3 consumption may improve metabolic health and may reduce the risk of cardiovascular disease. Additionally, omega-3s may also be beneficial and are being researched for other conditions, including reducing cancer risk and macular degeneration.

\subsection{Prebiotic and Probiotics}

Probiotics are live microorganisms, whereas prebiotics is fermented products that alter the gut microbiome [59] [60]. Probiotics can help with atopic dermatitis and some digestive issues but have not been shown to have major benefits in the healthy general population [59]. The effectiveness of probiotics is dependent upon the strain of bacteria used, the amount taken, and the duration of use. Individuals with irritable bowel syndrome (IBS) may find some relief through probiotics depending on their symptoms. Prebiotics has been shown to improve symptoms of traveler's diarrhea, while probiotics improved symptoms of acute diarrhea caused by antibiotics. Probiotics may also help with other medical conditions such as obesity and hypercholesterolemia (high cholesterol), but research is inconclusive.

\subsection{Summary}

The above is simply a brief example of some dietary supplements that have been shown to have efficacy for general purposes. Many more examples can be found by searching the medical databases, both for general health and for specific health conditions and sporting activities. For example, beetroot extract has received considerable attention in recent years as an aid to both lower blood pressure [61] in those with hypertension and to improve athletic performance [62]. Creatine monohydrate is another example, which has literally hundreds of stu- 
dies supporting its efficacy for athletic performance [63], with others highlighting the benefits of this agent in treating certain diseases [64] [65].

Guiding patients through the complex options available in today's dietary supplement market requires in-depth knowledge of functional foods, dietary supplements, and nutraceuticals. When determining the cogency of using dietary supplement, cost of supplements must be considered alongside need, efficacy, and medication options. First and foremost, however, should be safety, including whether consuming the supplement would put the patient at a significant risk of adverse effects or interactions with medications they may be taking. If one or more dietary supplements are to be used, it should be determined that the dosage of each ingredient (taking into account diet and the individual's health) falls within safe daily intake recommendations.

\section{Conclusion}

It is important for healthcare professionals to maintain at least a basic understanding of dietary supplements, in order to better communicate with their patients who are using these products. Armed with a more in-depth knowledge of supplements, providers can better assist patients in weighing the potential benefits and risks. Should adverse events occur, healthcare providers should guide patients in reporting these, in an attempt to make the dietary supplement market safer. Those interested in additional information about specific supplements, can utilize the ODS website, Dietary Supplement Label Database, and other resources outlined by the ADA and the publication by Asher [19] [26] [66] [67].

\section{Conflicts of Interest}

The authors declare no conflicts of interest regarding the publication of this paper.

\section{References}

[1] Dietary Supplement Health and Education Act of 1994. https://ods.od.nih.gov/About/DSHEA Wording.aspx

[2] 2019 CRN Consumer Survey on Dietary Supplements: Consumer Intelligence to Enhance Business Outcomes. Council for Responsible Nutrition.

https://www.crnusa.org/resources/2019-crn-consumer-survey-dietary-supplementsconsumer-intelligence-enhance-business

[3] Blumberg, J.B., Frei, B.B., Fulgoni, V.L., Weaver, C.M. and Zeisel, S.H. (2017) Impact of Frequency of Multi-Vitamin/Multi-Mineral Supplement Intake on Nutritional Adequacy and Nutrient Deficiencies in U.S. Adults. Nutrients, 9, 849. https://doi.org/10.3390/nu9080849

[4] Cowan, A., Jun, S., Bhadra, A., Dodd, K., Dwyer, J., Eicher-Miller, H., Gahche, J., Potischman, N., Tooze, J. and Bailey, R. (2019) Dietary Supplements Contributed Substantially to Total Intakes and Nutritional Adequacy of Several Micronutrients Among U.S. Adults, NHANES 2011-2014 (OR14-07-19). Current Developments in Nutrition, 3. https://doi.org/10.1093/cdn/nzz039.OR14-07-19

[5] Wallace, T.C., McBurney, M. and Fulgoni, V.L. (2014) Multivitamin/Mineral Sup- 
plement Contribution to Micronutrient Intakes in the United States, 2007-2010. Journal of the American College of Nutrition, 33, 94-102. https://doi.org/10.1080/07315724.2013.846806

[6] Tulchinsky, T.H. (2010) Micronutrient Deficiency Conditions: Global Health Issues. Public Health Reviews, 32, 243-255. https://doi.org/10.1007/BF03391600

[7] A Closer Look at Current Intakes and Recommended Shifts-2015-2020 Dietary Guidelines. health.gov.

https://health.gov/our-work/food-nutrition/2015-2020-dietary-guidelines/guideline s/chapter-2/a-closer-look-at-current-intakes-and-recommended-shifts/\#undercons umed-nutrients

[8] Bird, J.K., Murphy, R.A., Ciappio, E.D. and McBurney, M.I. (2017) Risk of Deficiency in Multiple Concurrent Micronutrients in Children and Adults in the United States. Nutrients, 9, 655. https://doi.org/10.3390/nu9070655

[9] Walrand, S. (2018) Dietary Supplement Intake among the Elderly: Hazards and Benefits. Current Opinion in Clinical Nutrition \& Metabolic Care, 21, 465-470. https://doi.org/10.1097/MCO.0000000000000512

[10] Kris-Etherton, P.M., Akabas, S.R., Bales, C.W., Bistrian, B., Braun, L., Edwards, M.S., Laur, C., Lenders, C.M., Levy, M.D., Palmer, C.A., Pratt, C.A., Ray, S., Rock, C.L., Saltzman, E., Seidner, D.L. and Van Horn, L. (2014) The Need to Advance Nutrition Education in the Training of Health Care Professionals and Recommended Research to Evaluate Implementation and Effectiveness. The American Journal of Clinical Nutrition, 99, 1153S-1166S. https://doi.org/10.3945/ajen.113.073502

[11] Van Horn, L., Lenders, C.M., Pratt, C.A., Beech, B., Carney, P.A., Dietz, W., DiMaria-Ghalili, R., Harlan, T., Hash, R., Kohlmeier, M., Kolasa, K., Krebs, N.F., Kushner, R.F., Lieh-Lai, M., Lindsley, J., Meacham, S., Nicastro, H., Nowson, C., Palmer, C., Paniagua, M., Philips, E., Ray, S., Rose, S., Salive, M., Schofield, M., Thompson, K., Trilk, J.L., Twillman, G., White, J.D., Zappalà, G., Vargas, A. and Lynch, C. (2019) Advancing Nutrition Education, Training, and Research for Medical Students, Residents, Fellows, Attending Physicians, and Other Clinicians: Building Competencies and Interdisciplinary Coordination. Advances in Nutrition (Bethesda, Md.), 10, 1181-1200. https://doi.org/10.1093/advances/nmz083

[12] DiMaria-Ghalili, R.A., Mirtallo, J.M., Tobin, B.W., Hark, L., Van Horn, L. and Palmer, C.A. (2014) Challenges and Opportunities for Nutrition Education and Training in the Health Care Professions: Intraprofessional and Interprofessional Call to Action. The American Journal of Clinical Nutrition, 99, 1184S-1193S. https://doi.org/10.3945/ajcn.113.073536

[13] Kemper, K.J., Gardiner, P., Gobble, J. and Woods, C. (2006) Expertise about Herbs and Dietary Supplements among Diverse Health Professionals. BMC Complementary and Alternative Medicine, 6, 15. https://doi.org/10.1186/1472-6882-6-15

[14] Statement from FDA Commissioner Scott Gottlieb, M.D., on the Agency's New Efforts to Strengthen Regulation of Dietary Supplements by Modernizing and Reforming FDA's Oversight.

https://www.fda.gov/news-events/press-announcements/statement-fda-commission er-scott-gottlieb-md-agencys-new-efforts-strengthen-regulation-dietary

[15] Mehta, D.H., Gardiner, P.M., Phillips, R.S. and McCarthy, E.P. (2008) Herbal and Dietary Supplement Disclosure to Health Care Providers by Individuals with Chronic Conditions. Journal of Alternative and Complementary Medicine (NeW York, N.Y.), 14, 1263-1269. https://doi.org/10.1089/acm.2008.0290

[16] Ronis, M.J.J., Pedersen, K.B. and Watt, J. (2018) Adverse Effects of Nutraceuticals 
and Dietary Supplements. Annual Review of Pharmacology and Toxicology, 58, 583-601. https://doi.org/10.1146/annurev-pharmtox-010617-052844

[17] Schmitz, S.M., Lopez, H.L., Mackay, D., Nguyen, H. and Miller, P.E. (2020) Serious Adverse Events Reported with Dietary Supplement Use in the United States: A 2.5 Year Experience. Journal of Dietary Supplements, 17, 227-248. https://doi.org/10.1080/19390211.2018.1513109

[18] Geller, A.I., Shehab, N., Weidle, N.J., Lovegrove, M.C., Wolpert, B.J., Timbo, B.B., Mozersky, R.P. and Budnitz, D.S. (2015) Emergency Department Visits for Adverse Events Related to Dietary Supplements. The New England Journal of Medicine, 373, 1531-1540. https://doi.org/10.1056/NEJMsa1504267

[19] Asher, G.N., Corbett, A.H. and Hawke, R.L. (2017) Common Herbal Dietary Supplement-Drug Interactions. American Family Physician, 96, 101-107.

[20] Fugh-Berman, A. (2000) Herb-Drug Interactions. The Lancet, 355, 134-138. https://doi.org/10.1016/S0140-6736(99)06457-0

[21] Gardiner, P., Filippelli, A.C., Sadikova, E., White, L.F. and Jack, B.W. (2015) Medication and Dietary Supplement Interactions among a Low-Income, Hospitalized Patient Population Who Take Cardiac Medications. Evidence-Based Complementary and Alternative Medicine, 2015, Article ID: 429826. https://doi.org/10.1155/2015/429826

[22] Office of Dietary Supplements-Vitamin K. https://ods.od.nih.gov/factsheets/VitaminK-Consumer

[23] Comparative Effectiveness of Dietary Supplement versus No Dietary Supplement Use in Adults Taking Cardiovascular Drugs. Effective Health Care Program. https://effectivehealthcare.ahrq.gov/products/dietary-supplements/research-protoco 1

[24] Woo, J.J. (2007) Adverse Event Monitoring and Multivitamin-Multimineral Dietary Supplements. The American Journal of Clinical Nutrition, 85, 323S-324S. https://doi.org/10.1093/ajcn/85.1.323S

[25] Vasilakes, J.A., Rizvi, R.F., Zhang, J., Adam, T.J. and Zhang, R. (2019) Detecting Signals of Dietary Supplement Adverse Events from the CFSAN Adverse Event Reporting System (CAERS). AMIA Summits on Translational Science Proceedings, 2019, 258-266.

[26] American Dietetic Association (2005) Practice Paper of the American Dietetic Association: Dietary Supplements. Journal of the American Dietetic Association, 105, 460-470. https://doi.org/10.1016/j.jada.2005.01.011

[27] Public Law 109-462-Dietary Supplement and Nonprescription Drug Consumer Protection Act-Content Details-PLAW-109publ462.

https://www.govinfo.gov/app/details/PLAW-109publ462

[28] H.R.3448-107th Congress (2001-2002): Public Health Security and Bioterrorism Preparedness and Response Act of 2002. https://www.congress.gov/bill/107th-congress/house-bill/3448

[29] Dietary Supplements. https://www.fda.gov/food/dietary-supplements

[30] FDA Center for Food Science and Applied Nutrition (2019) Food Allergen Labeling and Consumer Protection Act of 2004 Questions and Answers.

https://www.fda.gov/food/food-allergensgluten-free-guidance-documents-regulator y-information/food-allergen-labeling-and-consumer-protection-act-2004-questions -and-answers

[31] Office of Dietary Supplements-Background Information: Dietary Supplements. 
https://ods.od.nih.gov/factsheets/DietarySupplements-Consumer/

[32] FDA Center for Food Safety and Applied Nutrition (2021) Authorized Health Claims That Meet the Significant Scientific Agreement (SSA) Standard.

https://www.fda.gov/food/food-labeling-nutrition/authorized-health-claims-meet-si gnificant-scientific-agreement-ssa-standard

[33] FDA Center for Food Safety and Applied Nutrition (2020) Announces New Qualified Health Claims for EPA and DHA Omega-3 Consumption and the Risk of Hypertension and Coronary Heart Disease.

https://www.fda.gov/food/cfsan-constituent-updates/fda-announces-new-qualifiedhealth-claims-epa-and-dha-omega-3-consumption-and-risk-hypertension-and

[34] Health Claims.

https://www.ftc.gov/news-events/media-resources/truth-advertising/health-claims

[35] Using Dietary Supplements Wisely. https://www.nccih.nih.gov/health/using-dietary-supplements-wisely

[36] Tainted Products Marketed as Dietary Supplements_CDER. https://www.accessdata.fda.gov/scripts/sda/sdNavigation.cfm?filter=\&sortColumn= $1 \mathrm{~d} \& s d=$ tainted supplements cder\&page $=1$

[37] Télessy, I.G. (2019) Chapter 24 Nutraceuticals. In: Singh, R.B., Watson, R.R. and Takahashi, T., Eds., The Role of Functional Food Security in Global Health, Academic Press, Cambridge, 409-421. https://doi.org/10.1016/B978-0-12-813148-0.00024-4

[38] Dwyer, J.T., Coates, P.M. and Smith, M.J. (2018) Dietary Supplements: Regulatory Challenges and Research Resources. Nutrients, 10, 41. https://doi.org/10.3390/nu10010041

[39] Gurley, B.J. (2010) Clinical Pharmacology and Dietary Supplements: An Evolving Relationship. Clinical Pharmacology \& Therapeutics, 87, 235-238.

https://doi.org/10.1038/clpt.2009.245

[40] Clinical Trials: Two-Thirds of Supplement Companies Support Research. https://www.naturalproductsinsider.com/claims/clinical-trials-two-thirds-suppleme nt-companies-support-research

[41] Zarin, D.A., Tse, T. and Sheehan, J. (2015) The Proposed Rule for U.S. Clinical Trial Registration and Results Submission. The New England Journal of Medicine, 372, 174-180. https://doi.org/10.1056/NEJMsr1414226

[42] He, Z., Rizvi, R.F., Yang, F., Adam, T.J. and Zhang, R. (2019) Comparing the Study Populations in Dietary Supplement and Drug Clinical Trials for Metabolic Syndrome and Related Disorders. AMIA Summits on Translational Science Proceedings, 2019, 799-808.

[43] ODS Strategic Plan 2017-2021. https://ods.od.nih.gov/About/StrategicPlan2017-2021.aspx

[44] Calder, P.C. (2017) Omega-3 Fatty Acids and Inflammatory Processes: From Molecules to Man. Biochemical Society Transactions, 45, 1105-1115. https://doi.org/10.1042/BST20160474

[45] Rahimlou, M., Asadi, M., Banaei Jahromi, N. and Mansoori, A. (2019) Alpha-Lipoic Acid (ALA) Supplementation Effect on Glycemic and Inflammatory Biomarkers: A Systematic Review and Meta-Analysis. Clinical Nutrition ESPEN, 32, 16-28. https://doi.org/10.1016/j.clnesp.2019.03.015

[46] Kelley, D.S., Adkins, Y. and Laugero, K.D. (2018) A Review of the Health Benefits of Cherries. Nutrients, 10, 368. https://doi.org/10.3390/nu10030368 
[47] Butawan, M., Benjamin, R.L. and Bloomer, R.J. (2017) Methylsulfonylmethane: Applications and Safety of a Novel Dietary Supplement. Nutrients, 9, 290. https://doi.org/10.3390/nu9030290

[48] Jalali, M., Mahmoodi, M., Moosavian, S.P., Jalali, R., Ferns, G., Mosallanezhad, A., Imanieh, M.H. and Mosallanezhad, Z. (2020) The Effects of Ginger Supplementation on Markers of Inflammatory and Oxidative Stress: A Systematic Review and Meta-Analysis of Clinical Trials. Phytotherapy Research, 34, 1723-1733. https://doi.org/10.1002/ptr.6638

[49] Musculoskeletal Inflammation and Natural Products: What the Science Says. https://www.nccih.nih.gov/health/providers/digest/musculoskeletal-inflammation-a nd-natural-products-science

[50] Maroon, J.C., Bost, J.W. and Maroon, A. (2010) Natural Anti-Inflammatory Agents for Pain Relief. Surgical Neurology International, 1, 80.

https://doi.org/10.4103/2152-7806.73804

[51] Office of Dietary Supplements-Calcium. https://ods.od.nih.gov/factsheets/Calcium-HealthProfessional

[52] Coenzyme Q10. https://www.nccih.nih.gov/health/coenzyme-q10

[53] Hernández-Camacho, J.D., Bernier, M., López-Lluch, G. and Navas, P. (2018) Coenzyme Q10 Supplementation in Aging and Disease. Frontiers in Physiology, 9, 44. https://doi.org/10.3389/fphys.2018.00044

[54] Qu, H., Guo, M., Chai, H., Wang, W., Gao, Z. and Shi, D. (2018) Effects of Coenzyme Q10 on Statin-Induced Myopathy: An Updated Meta-Analysis of Randomized Controlled Trials. Journal of the American Heart Association, 7, e009835. https://doi.org/10.1161/JAHA.118.009835

[55] Office of Dietary Supplements-Vitamin D https://ods.od.nih.gov/factsheets/VitaminD-HealthProfessional

[56] AREDS/AREDS2 Clinical Trials. National Eye Institute. https://www.nei.nih.gov/research/clinical-trials/age-related-eye-disease-studies-are dsareds2/about-areds-and-areds2

[57] Office of Dietary Supplements-Folate. https://ods.od.nih.gov/factsheets/Folate-Consumer

[58] Office of Dietary Supplements-Omega-3 Fatty Acids. https://ods.od.nih.gov/factsheets/Omega3FattyAcids-HealthProfessional

[59] Office of Dietary Supplements-Probiotics. https://ods.od.nih.gov/factsheets/Probiotics-HealthProfessional

[60] Sanders, M.E., Lenoir-Wijnkoop, I., Salminen, S., Merenstein, D.J., Gibson, G.R., Petschow, B.W., Nieuwdorp, M., Tancredi, D.J., Cifelli, C.J., Jacques, P. and Pot, B. (2014) Probiotics and Prebiotics: Prospects for Public Health and Nutritional Recommendations. Annals of the New York Academy of Sciences, 1309, 19-29. https://doi.org/10.1111/nyas.12377

[61] Bonilla Ocampo, D., Paipilla, A., Marín, E., Vargas-Molina, S., Petro, J. and Pérez-Idárraga, A. (2018) Dietary Nitrate from Beetroot Juice for Hypertension: A Systematic Review. Biomolecules, 8, 134. https://doi.org/10.3390/biom8040134

[62] Domínguez, R., Cuenca, E., Maté-Muñoz, J., García-Fernández, P., Serra-Paya, N., Estevan, M., Herreros, P. and Garnacho-Castaño, M. (2017) Effects of Beetroot Juice Supplementation on Cardiorespiratory Endurance in Athletes. A Systematic Review. Nutrients, 9, 43. https://doi.org/10.3390/nu9010043

[63] Kreider, R.B., Kalman, D.S., Antonio, J., Ziegenfuss, T.N., Wildman, R., Collins, R., 
Candow, D.G., Kleiner, S.M., Almada, A.L. and Lopez, H.L. (2017) International Society of Sports Nutrition Position Stand: Safety and Efficacy of Creatine Supplementation in Exercise, Sport, and Medicine. Journal of the International Society of Sports Nutrition, 14, 18. https://doi.org/10.1186/s12970-017-0173-Z

[64] Dolan, E., Gualano, B. and Rawson, E.S. (2019) Beyond Muscle: The Effects of Creatine Supplementation on Brain Creatine, Cognitive Processing, and Traumatic Brain Injury. European Journal of Sport Science, 19, 1-14.

https://doi.org/10.1080/17461391.2018.1500644

[65] Marques, E.P. and Wyse, A.T.S. (2019) Creatine as a Neuroprotector: An Actor That Can Play Many Parts. Neurotoxicity Research, 36, 411-423.

https://doi.org/10.1007/s12640-019-00053-7

[66] Dietary Supplement Fact Sheets. https://ods.od.nih.gov/factsheets/list-all

[67] Dietary Supplement Label Database (DSLD).

https://www.dsld.nlm.nih.gov/dsld/index.jsp 